\title{
Asexual Reproduction of Phytophthora capsici as Affected by Extracts from Agricultural and Nonagricultural Soils
}

\author{
S. Sanogo \\ Department of Entomology, Plant Pathology, and Weed Science; New Mexico State University, Las Cruces 88003. \\ Accepted for publication 7 March 2007.
}

\section{ABSTRACT}

Sanogo, S. 2007. Asexual reproduction of Phytophthora capsici as affected by extracts from agricultural and nonagricultural soils. Phytopathology 97:873-878.

Formation of sporangia and zoospores in species of Phytophthora is known to be influenced by soil microbial and chemical composition. In Phytophthora capsici, the study of the relationship of soil chemical composition to production of sporangia and zoospores has been limited. $P$. capsici is a soilborne pathogen of a wide array of vegetable crops, including chile pepper (Capsicum апnиит) in New Mexico. Production of sporangia and zoospores by $P$. capsici was evaluated in extracts of soils from three different environments in New Mexico: (i) agricultural environments with a long history of chile pepper cropping and occurrence of $P$. capsici (CP), (ii) agricultural environments with no history of chile pepper cropping and no occurrence of P. capsici (Non-CP), and (iii) nonagricultural environments consisting of forests and rangelands (Non$\mathrm{Ag}$ ). There was a significant difference in production of $P$. capsici asexual propagules, expressed as natural log (number of sporangia $\times$ number of zoospores), among the three environments $(P=0.0298)$. Production of propagules was 9 to $13 \%$ greater in Non-Ag than in CP or Non-CP environments. Stepwise multiple discriminant analysis and canonical discriminant analysis identified the edaphic variables $\mathrm{Na}, \mathrm{pH}, \mathrm{P}$, organic matter content, and asexual propagule production as contributing the most to the separation of the three environments. Two significant $(P<0.0001)$ canonical discriminant functions were derived with the first function, accounting for $\approx 75 \%$ of the explained variance. Based on the two discriminant functions, $\approx 93,86$, and $89 \%$ of observations in CP, Non-CP, and Non-Ag environments, respectively, were classified correctly. Soils from agricultural and nonagricultural environments differentially influence production of sporangia and zoospores in $P$. capsici, and soil samples could be effectively classified into agricultural and nonagricultural environments based on soil chemical properties and the production of asexual propagules by $P$. capsici in soil extracts.

Additional keyword: oomycete.
Phytophthora capsici is a devastating soilborne pathogen causing Phytophthora blight on chile pepper (Capsicum annuum) in New Mexico. This oomycete has been shown to spread under high soil moisture conditions $(7,16,20,21)$ and cause crop loss in a wide array of crops (10). Outbreaks of disease caused by P. capsici under high soil moisture conditions could be explained by an increased production of dispersal propagules such as sporangia and zoospores. The increased production of these propagules may be due to several factors, including stimulatory soil microorganisms and soil chemical composition (10).

Soil extracts commonly are used to induce production of sporangia and zoospores in Phytophthora spp. $(10,17)$. Production of these propagules has been known to be influenced by the microbial and chemical composition of soil since the early part of the 20th century $(4,18)$. In nonsterile soil extracts, increased formation of sporangia and release of zoospores by Phytophthora spp. have been reported $(4,6,18)$. This increased production of asexual propagules was associated with the presence of several telluric bacteria in the soil extracts $(4,6,18)$. When oospores of $P$. megasperma f. sp. glycinea were placed in sterile and nonsterile soil extracts, 32 and $38 \%$ germinated and produced sporangia, respectively; whereas, in water, only $5 \%$ germinated and produced sporangia (14).

In $P$. capsici, the roles of bacteria and soil chemical properties in inducing sporangia and zoospore production have not been well researched. In a study examining the germination of

Corresponding author: S. Sanogo; E-mail address: ssanogo@nmsu.edu

doi:10.1094/PHYTO-97-7-0873

(c) 2007 The American Phytopathological Society oospores, Hord and Ristaino (13) found that sporangia were produced more rapidly from oospores germinated in soil extract than from those germinated in distilled water. The rapid formation of sporangia in soil extract was postulated to be due to chemical factors present in soil extract. This postulation is tenable because the soil extract was sterilized by filtration and, thus, the involvement of any microbial factor was minimized or excluded. However, no chemical analysis was performed on the soil extract or on the soil from which the extract was prepared.

In a comparative study of Hawaiian soils suppressive and conducive to $P$. capsici, Ko and Nishijima (15) found that sporangial germination was 1,2 , and $3 \%$ in the sand, silt, and clay fractions, respectively, for the suppressive soil, and 80,76 , and $78 \%$, respectively, for the conducive soil. From these results, it was suggested that sporangial germination was inhibited in the suppressive soil by the physical and chemical characteristics of inorganic soil particles. However, the relationship of soil physical and chemical composition to sporangial germination was not explicitly examined.

There has been no systematic study on the relationship of soil chemical composition to production of sporangia and zoospores by $P$. capsici, although one study has examined the effect of soil $\mathrm{pH}$ on direct sporangial germination (2). In a survey of soil suppressiveness to three Phytophthora spp. (P. parasitica, P. palmivora, and $P$. capsici) in Taiwan, Ann (2) reported that, in general, soils with $\mathrm{pH}<7$ were more suppressive than soils with $\mathrm{pH}>7$. There was a significant positive correlation $(r=0.65)$ between $\mathrm{pH}$ and sporangial germination for $P$. capsici; however, no other chemical analyses were performed on the sampled soils.

Studies on the relationship of soil chemical composition to the production of sporangia and zoospores are important from at least two perspectives. First, these studies will expand the current eco- 
logical knowledgebase of $P$. capsici. Second, assessment of the relationship between soil chemical composition and formation of sporangia and zoospores by $P$. capsici will provide a framework for assessing soil receptivity to $P$. capsici defined herein as the effect of soil on the ability of $P$. capsici to produce asexual propagules in soil. The concept of soil receptivity was first proposed by Alabouvette et al. (1) to describe the effect of soil on inoculum potential and may be used to predict the behavior of pathogens in different soils.

The goal of this study was to evaluate the production of sporangia and zoospores in soil extracts from agricultural and nonagricultural environments, with emphasis on the analysis of the chemical composition of soil from these environments. The impetus for this study arose from the above-described lack of knowledge of the relationship between soil chemical composition and production of propagules. Additionally, observations made by chile producers in southern New Mexico have asserted the occurrence of disease outbreaks and decline in chile pepper yield in virgin soils after two to three cropping seasons. Whether naturally occurring or introduced, the presence of $P$. capsici in those fields has raised concern about the ecology of this pathogen. Although a myriad of factors may be involved in P. capsici ecology, the present study focused on the relationship of soil chemical composition to sporangia and zoospore production by $P$. capsici, which has, to date, not been explored.

The specific objectives of this study were to (i) determine whether soil receptivity to asexual reproduction of $P$. capsici varied among soils from agricultural and nonagricultural environments and (ii) identify edaphic factors that significantly contributed to the distinction among agricultural and nonagricultural environments.

\section{MATERIALS AND METHODS}

Soil collection. Soil samples were collected from 66 sites which included agricultural fields $(n=57)$ and nonagricultural areas $(n=9)$. Soil collection in agricultural fields was performed in two contrasting agricultural environments, herein referred to as chile-Phytophthora (CP) and non-chile-Phytophthora (Non-CP). The CP environment $(n=43)$ encompasses southwestern New Mexico, a region which accounts for most of the chile pepper production in the state. In 2003, the four major counties in this region accounted for $\approx 93 \%$ of chile pepper production (3). Chile pepper is grown either continuously or in rotation with crops such as cotton (Gossypium hirsutum), alfalfa (Medicago sativa), corn (Zea mays), onion (Allium cepa), and pumpkin (Cucurbita pepo). Furrow irrigation is the most widely practiced method for supplying water to crops. Phytophthora blight and Verticillium wilt are the major soilborne diseases encountered on chile pepper in southwestern New Mexico (22).

The Non-CP environment $(n=14)$ encompasses two counties in eastern New Mexico. The primary crop produced in this area is peanut (Arachis hypogaea), which is occasionally rotated with crops such as wheat (Triticum aestivum), sorghum (Sorghum bicolor), cotton (G. hirsutum), and corn (Z. mays). Sprinkler irrigation is the most widely practiced method used in peanut fields. Because of the long-term cultivation of peanut in these counties, soilborne pathogens causing various diseases such as pod rot are the primary disease concerns.

The nonagricultural (Non-Ag) environment $(n=9)$ encompasses forest and rangeland areas, with selected sites located in northern New Mexico. These areas have not experienced any disturbance such as tillage and cropping.

In each of the 66 sites across the three environments, five soil subsamples were collected with a shovel to a depth of $20 \mathrm{~cm}$ at various locations within each site (26) following a W path. Soil subsamples were combined for each site to produce a composite sample. Soils were sieved through a 5-mm sieve, air dried on a laboratory bench at room temperature $\left(23\right.$ to $\left.25^{\circ} \mathrm{C}\right)$ for a week, and stored in plastic containers with screw caps in a $4^{\circ} \mathrm{C}$ cold room until use. Chemical properties of the soil samples were analyzed by the Soil and Water Testing Laboratory at New Mexico State University, Las Cruces. In the agricultural environments, soil sampling was conducted when chile pepper was at the growth stage from green pod to red pod, and peanut was at the early flowering stage.

Preparation of soil extract and production of sporangia and zoospores. To prepare soil extracts, $20 \mathrm{~g}$ of soil was added to a liter of sterile deionized water in a 2,000-ml flask. A magnetic stirring rod was placed in the flask, and soil and water were agitated for $8 \mathrm{~h}$ on a magnetic stirrer. Then, the solution was left to decant for $\approx 16 \mathrm{~h}$, and the supernatant was vacuum filtered through a Whatman no. 1 paper filter and a Millipore filter $(0.22-\mu \mathrm{m})$. The filtrate was stored at $4^{\circ} \mathrm{C}$ until use. Before use, each filtrate was removed from the cold storage and placed on a laboratory bench at room temperature $\left(23\right.$ to $\left.25^{\circ} \mathrm{C}\right)$ for $60 \mathrm{~min}$.

To test the effect of filtrate on sporangia formation and zoospore production, a modified procedure from Rasmussen and Stanghellini (19) was used. The isolate of $P$. capsici used (isolate PWB24) is the most virulent isolate routinely employed in the chile pepper breeding program for screening lines for disease resistance at New Mexico State University (5). Three 1-cmdiameter plugs of $P$. capsici from a 5-day-old culture grown on $10 \% \mathrm{~V} 8$ agar were placed in a 9-cm-diameter petri plate, and $20 \mathrm{ml}$ of soil extract was added to the plate. Three plates were prepared using each soil extract, and plates were incubated at $25^{\circ} \mathrm{C}$ in the dark. For controls, plugs were placed in sterile deionized water. After $48 \mathrm{~h}$, the plugs were observed with a compound microscope at $\times 40$ magnification. Sporangia were counted in five arbitrarily selected fields of view along the periphery of each plug following a clockwise path. Then, the plates were placed at $10^{\circ} \mathrm{C}$ for $45 \mathrm{~min}$, and maintained in an incubator at $25^{\circ} \mathrm{C}$ in the dark for $90 \mathrm{~min}$. The suspension was filtered through two layers of cheesecloth and vigorously mixed. Suspension $(1 \mathrm{ml})$ was dispensed to a $1.5-\mathrm{ml}$ microcentrifuge tube to which $100 \mu \mathrm{l}$ of acid fuchsin also was added. The tube was shaken vigorously, and the number of zoospores per milliliter in the acid fuchsin-treated suspension was counted with a hemacytometer. Five sporangia counts per mycelial plug and two zoospore counts were made on each plate; thus, the data collected consisted of the number of sporangia (per 15 fields of view) and zoospores per three mycelial plugs. The number of sporangia and the number of zoospores produced in soil extracts were adjusted by subtracting the number of sporangia and zoospores produced in sterile deionized water (control). This adjustment was applied to separate the level of asexual propagule production in soil extracts from the level of production in water alone. For data analysis, only the adjusted numbers of propagules produced in soil extracts were used. The entire experiment was completed twice.

Data analysis. Data consisting of biological and physical variables were collected. The biological variable was the number of asexual propagules (LPRO) and was expressed as the natural logarithm (number of sporangia $\times$ number of zoospores) produced per plate (three mycelial plugs per plate). This variable was chosen because it provides a measure of the inoculum potential of $P$. capsici by incorporating the two most important biological components of that inoculum potential. The physical variables included the various characteristics of each soil sample and were: $\mathrm{pH}$, electrical conductivity (EC), calcium $(\mathrm{Ca})$, copper $(\mathrm{Cu})$, magnesium $(\mathrm{Mg})$, manganese $(\mathrm{Mn})$, nitrate-nitrogen $\left(\mathrm{NO}_{3}-\mathrm{N}\right)$, organic matter $(\mathrm{OM})$, potassium $(\mathrm{K})$, phosphorus $(\mathrm{P})$, and sodium $(\mathrm{Na})$. For each of these variables, the following descriptive statistics were obtained or computed: mean, standard deviation, minimum, and maximum. Pearson's product-moment correlation coefficients were computed to assess the strength of association among variables within each environment. 
Two multivariate analyses were performed: stepwise multiple discriminant analysis and canonical discriminant analysis $(11,23$, 25). Stepwise discriminant analysis was used to identify variables that were most important in delineating the differences among the $\mathrm{CP}$, Non-CP, and Non-Ag environments. This analysis was conducted using the SAS STEPDISC procedure (SAS Institute Inc., Cary, NC). Based on the best subset of variables identified by stepwise discriminant analysis, discriminant functions were derived for classifying each observation into the three groups $(\mathrm{CP}$, Non-CP, and Non-Ag). The goal of discriminant analysis is to assess the relationship between a single nonmetric dependent variable with two or more levels and a set of several metric independent variables $(11,23,25)$. The data collected in this study consisted of a nonmetric dependent variable, environment, with three levels (CP, Non-CP, and Non-Ag) and several metric variables (edaphic variables and production of propagules). Discriminant analysis was judged appropriate based on the nature of the data collected and the goal of the study.

Two methods for assessing the reliability of classification were used: error count estimate and posterior probability error rate estimate. Error count estimate can be obtained with reduced bias through cross-validation by the omission method. In this method, each observation was omitted in turn, and a discriminant analysis was performed with the remaining observations. The functions derived then were used to classify the omitted observation. This method was carried out using the SAS DISCRIM procedure with the CROSSLIST option (SAS Institute Inc.). The percentages of correctly classified observations (hit ratio) were calculated and used as a measure of the reliability of the discriminant functions. To further assess the accuracy of classification, the percentages of correctly classified observations (hit ratio) were compared with the maximum chance criterion (11), which is defined as the highest frequency of occurrence among groups. In this case, there were 66 observations with 43,14, and 9 observations in CP, Non$\mathrm{CP}$, and Non-Ag environments, respectively. Therefore, the highest frequency of occurrence was found in the $\mathrm{CP}$ group at $65 \%$ (obtained by dividing 43 by 66 and multiplying the quotient by $100)$. If the hit ratio exceeds $65 \%$, then validity of the discriminant model is concluded. Posterior probabilities, as the name implies, provide the probability of an observation being allocated to a particular membership group based on its discriminant score.

Canonical discriminant analysis was performed to assess the strength of the association of the set of variables (best set identified by stepwise discriminant analysis) with the three environments defined in this study. Standardized canonical coefficients and canonical correlation coefficients (also called canonical loadings) were used to gauge the significance of variables in the canonical functions. Coefficients with a value of 0.3 or greater were considered significant for interpretation $(11,24)$ Canonical discriminant analysis was carried out using the SAS CANDISC procedure (SAS Institute Inc.).

Prior to performing various analyses, transformations were implemented to achieve normality for several variables, and included natural logarithm, logit, and square root transformations. Data on propagule production were combined for both experiments because data were consistent between both experiments. Significance of all statistical analyses was assessed at a probability level of 0.05 .

\section{RESULTS}

Descriptive statistics for each variable within each type of environment (CP, Non-CP, Non-Ag) are shown in Table 1. The highest mean for $\mathrm{pH}, \mathrm{EC}, \mathrm{Na}, \mathrm{Ca}, \mathrm{Mg}, \mathrm{NO}_{3}-\mathrm{N}, \mathrm{P}, \mathrm{Cu}$, and $\mathrm{Mn}$ was recorded on soil samples collected in the $\mathrm{CP}$ environment. Soil samples from the Non-CP environment had the highest mean for $\mathrm{K}$, whereas the highest mean for OM and LPRO was recorded on soil samples from Non-Ag environment.

The LPRO produced by $P$. capsici in soil extracts was significantly different among the three environments $(P=0.0298)$. Production of asexual propagules was $\approx 9$ to $13 \%$ greater in the Non-Ag environment than in the CP and Non-CP environments, respectively. Regardless of environment, when all soil samples were categorized into groups with $\mathrm{pH}>7$ or $\mathrm{pH}<7,86 \%$ of the samples had $\mathrm{pH}>7$ whereas $14 \%$ had $\mathrm{pH}<7$. Asexual propagule production in both groups was similar according to $t$ test $(P=$ 0.424).

The significance of Pearson's product-moment correlation coefficients varied within each type of environment. In the $\mathrm{CP}$ environment, significant positive correlation coefficients $(P<0.003)$ were found between the LPRO produced and the levels of $\mathrm{Ca}, \mathrm{EC}$, $\mathrm{Mg}, \mathrm{Mn}, \mathrm{Na}, \mathrm{NO}_{3}$, and $\mathrm{K}$ (Table 2). The highest and lowest statistically significant correlation coefficients were 0.68 and 0.44 , respectively. In the Non-CP environment, a statistically significant negative correlation $(r=-0.55, P=0.0397)$ occurred between the number of propagules and $\mathrm{K}$ (Table 2 ). There were no significant correlations between soil variables and LPRO produced for soil samples from Non-Ag environments (Table 2).

The variables consisting of $\mathrm{Na}, \mathrm{pH}, \mathrm{P}, \mathrm{OM}$, and $\mathrm{LPRO}$ were identified by stepwise discriminant analysis as contributing the most to the separation of $\mathrm{CP}$, Non- $\mathrm{CP}$, and Non-Ag environments. Two significant $(P<0.0001)$ canonical discriminant functions were derived with the first function, accounting for $\approx 75 \%$ of the explained variance. The first function separated $\mathrm{CP}$ from Non-CP

TABLE 1. Mean, minimum (Min), and maximum (Max) of soil characteristics and production of asexual propagules by Phytophthora capsici from chilePhytophthora (CP), non-chile-Phytophthora (Non-CP), and nonagricultural (Non-Ag) environments

\begin{tabular}{|c|c|c|c|c|c|c|c|c|c|}
\hline \multirow[b]{3}{*}{ Variable $^{\mathrm{a}}$} & \multicolumn{9}{|c|}{ Environment } \\
\hline & \multicolumn{3}{|c|}{$\mathrm{CP}$} & \multicolumn{3}{|c|}{ Non-CP } & \multicolumn{3}{|c|}{ Non-Ag } \\
\hline & Mean & Min & $\operatorname{Max}$ & Mean & Min & $\operatorname{Max}$ & Mean & Min & $\operatorname{Max}$ \\
\hline $\mathrm{EC}(\mathrm{mmhos} / \mathrm{cm})$ & 3.23 & 0.39 & 15.8 & 1.15 & 0.45 & 3.55 & 0.85 & 0.28 & 2.25 \\
\hline $\mathrm{Na}$ (meq/liter) & 15.21 & 0.89 & 128 & 1.64 & 0.18 & 5.09 & 0.796 & 0.2 & 2.1 \\
\hline $\mathrm{Ca}$ (meq/liter) & 16.16 & 3.1 & 57.3 & 6.32 & 3.07 & 17.6 & 7.09 & 2.68 & 16.7 \\
\hline Mg (meq/liter) & 5.17 & 0.6 & 21.5 & 3.01 & 1.06 & 7.99 & 1.81 & 0.5 & 5.58 \\
\hline $\mathrm{K}(\mathrm{mg} / \mathrm{kg})$ & 61.42 & 10 & 388 & 67.78 & 31 & 113 & 42.22 & 9 & 114 \\
\hline $\mathrm{P}(\mathrm{mg} / \mathrm{kg})$ & 29.98 & 5.2 & 147 & 18.92 & 5.2 & 60 & 9.17 & 0.8 & 21.2 \\
\hline $\mathrm{Cu}(\mathrm{mg} / \mathrm{kg})$ & 1.63 & 0.48 & 3.14 & 0.59 & 0.25 & 1.05 & 0.91 & 0.21 & 2.89 \\
\hline $\mathrm{Mn}(\mathrm{mg} / \mathrm{kg})$ & 8.49 & 1.73 & 22.1 & 3.78 & 2.31 & 6.50 & 7.23 & 2.31 & 11.4 \\
\hline LPRO & 15.24 & 11.20 & 18 & 14.6 & 12.4 & 16 & 16.5 & 14.5 & 17.5 \\
\hline
\end{tabular}

${ }^{a} \mathrm{EC}=$ electrical conductivity, $\mathrm{Na}=$ sodium, $\mathrm{Ca}=$ calcium, $\mathrm{Mg}=$ magnesium, $\mathrm{NO}_{3}-\mathrm{N}=$ nitrate-nitrogen, $\mathrm{OM}=$ organic matter, $\mathrm{K}=$ potassium, $\mathrm{P}=$ phosphorus, $\mathrm{Cu}=$ copper, $\mathrm{Mn}=$ manganese, and LPRO = number of asexual propagules. Mean, minimum, and maximum are statistics for nontransformed variables except for variable LPRO, which is expressed as natural $\log$ (number of sporangia $\times$ number of zoospores). Units of measurement are shown in parentheses. 
and Non-Ag environments, whereas the second function separated Non-Ag from CP and Non-CP environments (Fig. 1). Canonical correlation between environment and the first canonical discriminant function was 0.83 , and canonical correlation between environment and the second canonical discriminant function was 0.66 .

Except for content in OM, the standardized canonical coefficients associated with all other variables $(\mathrm{Na}, \mathrm{pH}, \mathrm{P}$, and LPRO) on the first canonical discriminant function were $>0.3$, a level considered significant for interpretation (Table 3). The positive sign of the standardized coefficients associated with $\mathrm{Na}, \mathrm{pH}$, and $\mathrm{P}$ suggests that these variables had a positive contribution to the discrimination power of the first canonical discriminant function,

TABLE 2. Pearson's product-moment correlation coefficients between production of asexual propagules by Phytophthora capsici, expressed as natural $\log$ (number of sporangia $\times$ number of zoospores), and soil variables within chile-Phytophthora (CP), non-chile-Phytophthora (Non-CP), and nonagricultural (Non-Ag) environments

\begin{tabular}{lccc}
\hline & \multicolumn{3}{c}{ Environment $^{\mathrm{b}}$} \\
\cline { 2 - 4 } Soil variable & $\mathrm{CP}$ & Non-CP & Non-Ag \\
\cline { 2 - 4 } $\mathrm{pH}$ & $-0.20(0.2278)$ & $0.19(0.5125)$ & $-0.06(0.8692)$ \\
$\mathrm{EC} \mathrm{(mmhos/cm)}$ & $0.52(0.0004)$ & $0.07(0.8244)$ & $0.15(0.7087)$ \\
$\mathrm{Na}(\mathrm{meq} / \mathrm{liter})$ & $0.49(0.0010)$ & $-0.15(0.6126)$ & $0.20(0.6129)$ \\
$\mathrm{Ca}(\mathrm{meq} / \mathrm{liter})$ & $0.47(0.0013)$ & $0.11(0.7070)$ & $0.20(0.5997)$ \\
$\mathrm{Cu}(\mathrm{mg} / \mathrm{Kg})$ & $0.38(0.0908)$ & $-0.18(0.88)$ & $0.20(0.66)$ \\
$\mathrm{Mg}(\mathrm{meq} / \mathrm{liter})$ & $0.46(0.0022)$ & $0.09(0.7509)$ & $0.14(0.7196)$ \\
$\mathrm{Mn}(\mathrm{mg} / \mathrm{kg})$ & $0.68(0.0009)$ & $0.01(0.99)$ & $0.29(0.51)$ \\
$\mathrm{NO}-\mathrm{N}(\mathrm{mg} / \mathrm{kg})$ & $0.44(0.0029)$ & $0.17(0.5632)$ & $0.40(0.2834)$ \\
$\mathrm{OM}(\%)$ & $-0.025(0.8712)$ & $-0.16(0.5945)$ & $0.43(0.2492)$ \\
$\mathrm{K}(\mathrm{mg} / \mathrm{kg})$ & $0.46(0.0017)$ & $-0.55(0.0397)$ & $-0.16(0.6740)$ \\
$\mathrm{P}(\mathrm{mg} / \mathrm{kg})$ & $0.25(0.1001)$ & $-0.49(0.0748)$ & $0.20(0.6089)$ \\
\hline
\end{tabular}

${ }^{\mathrm{a}} \mathrm{EC}=$ electrical conductivity, $\mathrm{Na}=$ sodium, $\mathrm{Ca}=$ calcium, $\mathrm{Cu}=$ copper, $\mathrm{Mg}=$ magnesium, $\mathrm{Mn}=$ manganese, $\mathrm{NO}_{3}-\mathrm{N}=$ nitrate-nitrogen, $\mathrm{OM}=$ organic matter, $\mathrm{K}=$ potassium, and $\mathrm{P}=$ phosphorus. Natural logarithm transformation was used for $\mathrm{EC}, \mathrm{Na}, \mathrm{Ca}, \mathrm{NO}_{3}-\mathrm{N}, \mathrm{OM}$, and $\mathrm{Mn}$. Logit transformation was used for $\mathrm{pH}$. Units of measurement are shown in parentheses.

b Numbers in parentheses are $P$ values.

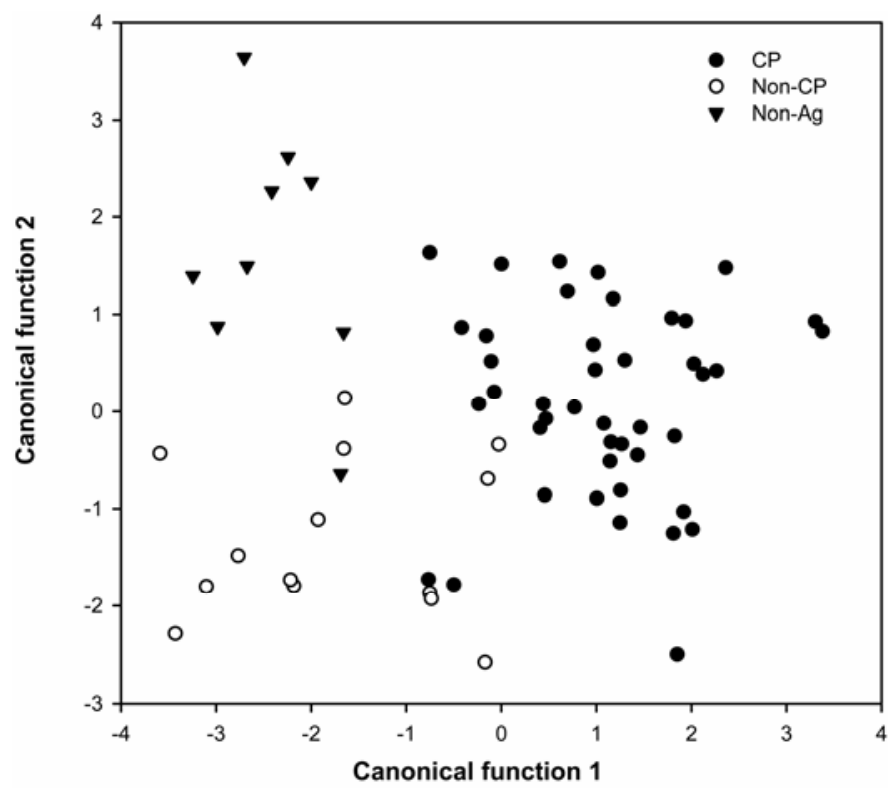

Fig. 1. Classification of soil samples into three groups based on first and second canonical functions. Solid circles, open circles, and solid triangles represent samples from chile-Phytophthora (CP), non-chile-Phytophthora (Non-CP), and nonagricultural (Non-Ag) environments, respectively. Stepwise multiple discriminant analysis and canonical discriminant analysis identified the edaphic variables $\mathrm{Na}, \mathrm{pH}, \mathrm{P}$, organic matter content, and asexual propagule production as contributing the most to the separation of the three environments. The first function accounted for $\approx 75 \%$ of the explained variance. in contrast to LPRO, which had a negative standardized canonical coefficient. With respect to the second canonical discriminant function (Table 3), the standardized canonical coefficients associated with all variables ( $\mathrm{pH}, \mathrm{OM}, \mathrm{P}$, and LPRO), except for $\mathrm{Na}$, were $>0.3$. The positive sign of the standardized coefficients associated with OM, $\mathrm{pH}$, and LPRO suggests that these variables contributed positively to the discrimination power of the second canonical discriminant function, in contrast to $\mathrm{P}$, which had a negative standardized canonical coefficient.

Examination of the coefficients of correlation between the first canonical discriminant function and the best-set variables (Table 3 ) indicated that $\mathrm{Na}$ and $\mathrm{pH}$ were the most significant discriminators (coefficient of correlation $\geq 0.30$ ). With regard to the second canonical discriminant function, significant coefficients of correlation $(\geq 0.30)$ were found with $\mathrm{OM}$ and production of propagules. However, it should be noted that the coefficients of correlation of both canonical functions with $\mathrm{P}$ and of the second canonical function with $\mathrm{pH}$ are relatively close to the 0.30 significance level for interpretation. All significant coefficients of correlation were positive except for the one associated with $\mathrm{P}$ with respect to the second canonical discriminant function. Thus, the first canonical discriminant function was completely defined by edaphic variables, whereas the second canonical discriminant function was determined by a combination of edaphic and biological variables.

The hit ratio was $92 \%$, which exceeded the maximum chance criterion of $65 \%$. In cross-validation based on the derived canonical discriminant functions, 93,86 , and $89 \%$ of observations in the $\mathrm{CP}$, Non-CP, and Non-Ag environments, respectively, were classified correctly. Posterior probability values for correctly classified observations ranged from 0.505 to 0.999 .

\section{DISCUSSION}

This study focused on the relationship of soil chemical composition to the production of asexual propagules involved in the dispersal of $P$. capsici. Based on the objectives of this study, three soil environments were identified and systematically examined for the relationship of soil chemical properties to asexual reproduction of $P$. capsici. The rationale for selecting these three soil environments was to increase variation in soil chemical characteristics and enable the establishment of a relationship of soil chemical composition with production of sporangia and zoospores by $P$. capsici.

The three environments were different in all variables examined, and the LPRO produced by $P$. capsici was one of the variables that significantly contributed to the distinction among

TABLE 3. Standardized canonical coefficients and coefficients of correlation of discriminant canonical functions with variables selected by stepwise discriminant analysis

\begin{tabular}{|c|c|c|c|c|}
\hline \multirow[b]{3}{*}{ Variables $^{\mathrm{a}}$} & \multicolumn{4}{|c|}{ Canonical discriminant functions ${ }^{b}$} \\
\hline & \multicolumn{2}{|c|}{ First } & \multicolumn{2}{|c|}{ Second } \\
\hline & Standard & Correlation & Standard & Correlation \\
\hline $\mathrm{Na}$ (meq/liter) & 0.94 & 0.68 & 0.05 & -0.009 \\
\hline $\mathrm{pH}$ & 0.72 & 0.33 & 0.42 & 0.25 \\
\hline $\mathrm{OM}(\%)$ & 0.11 & -0.02 & 0.90 & 0.64 \\
\hline LPRO & -0.38 & -0.05 & 0.46 & 0.38 \\
\hline $\mathrm{P}(\mathrm{mg} / \mathrm{kg})$ & 0.36 & 0.27 & -0.49 & -0.29 \\
\hline
\end{tabular}

a $\mathrm{Na}=$ sodium, $\mathrm{OM}=$ organic matter, $\mathrm{LPRO}=$ number of asexual propagules, and $\mathrm{P}=$ phosphorus. Natural logarithm transformation was used for $\mathrm{Na}, \mathrm{OM}$, and P. Logit transformation was used for $\mathrm{pH}$. LPRO production was expressed as natural $\log$ (number of sporangia $\times$ number of zoospores). Units of measurement are shown in parentheses.

b Standardized canonical coefficients and canonical correlation coefficients were used to gauge the significance of variables in the canonical functions. Coefficients $\geq 0.3$ were considered significant for interpretation. Standard = standardized coefficients and Correlation $=$ variable-function correlation . 
environments. Production of asexual propagules by $P$. capsici was greater in the Non-Ag environment than in the CP or Non-CP environments. These results, which suggest greater receptivity to reproduction of $P$. capsici in extracts of nonagricultural soils than in extracts of agricultural soils, may help explain the observation of disease outbreaks in virgin soils. Multiple discriminant and canonical discriminant analyses corroborated the characterization of the three defined environments based on the levels of sodium, $\mathrm{pH}, \mathrm{OM}$ content, phosphorus, and LPRO production. The validity of the canonical discriminant functions was supported with the high percentage of observations correctly classified in each soil environment.

This study is comparative and observational in nature, and does not involve any preassigned levels for the variables measured. Therefore, it is not possible to unequivocally establish a causeand-effect relationship among variables, even though significant correlations were found among some variables. Nonetheless, multiple discriminant and canonical discriminant analyses have enabled the identification of variables with significant discriminatory power for classifying soils into the three environments. The functions generated should enable prediction or classification of new cases. Discriminant analysis has been used extensively in phytopathological research (23) for description of the structure of association among variables and prediction of membership $(8,12$, 27). This study is the first to use discriminant and canonical discriminant analyses to assess differences among agricultural and nonagricultural environments based on a set of physical variables and production of sporangia and zoospores by $P$. capsici.

The emphasis in this study has been on the production of asexual propagules because of their role in dispersal of $P$. capsici. It is assumed that high soil receptivity may serve as a gauge for predicting the behavior of $P$. capsici in soil based on soil chemical composition. However, soil receptivity as assessed by levels of production of asexual propagules may not necessarily imply equivalent levels of plant infection. It is further assumed that soil chemical composition would affect production of asexual propagules independently of soil microbial composition. Soil extracts were filter sterilized in an attempt to disentangle the effect of soil chemical composition from the effect of microbial composition on production of asexual propagules. The physical removal of soil microbes by microfiltration was a sound methodological approach to minimize or eliminate any metabolites produced by these microbes which may influence the chemical composition of soil extracts. However, it is plausible that microbial metabolites may have been excreted into the extracts prior to microfiltration. It is not known to what extent these metabolites were present in the soil extracts and if they influenced the results obtained. In addition to microbial metabolites, root exudates from plants and soil-applied pesticides and fertilizers at soil sampling sites may have affected soil chemical composition. The influence of these factors was beyond the scope of this study. It is recognized that soil chemical composition, soil microbial composition, vegetation composition, and agricultural inputs (pesticides and fertilizers) may interactively influence the ability of $P$. capsici to produce propagules in soil. Such interactive effects merit further investigation.

The use of soil extracts $(4,6,10,17)$ provides an experimental approach that is easy to implement for assessing the receptivity of soil to $P$. capsici. Extracts from soil as prepared in this study were assumed to represent soil solution as found in situ under field conditions. It was further assumed that the concentration of soil extract used was within the range of soil solution concentration that may be encountered under field conditions. However, it should be recognized that concentration of soil solution may vary depending on several factors, such as amount of water applied during irrigation, rainfall, and organic and inorganic amendments incorporated into soil.

Soil extracts have been prepared at various concentrations (soil weight to volume of water) from $1 \%(1: 100)$ to $100 \%(1: 1)$ with several Phytophthora spp. $(4,6,9,13,17)$. Working with $P$. capsici, Matheron and Porchas (17) used nonsterile soil extract at $1.5 \%$ whereas Hord and Ristaino (13) employed $100 \%$. It is not known how these differences in concentration of soil extract affect production and germination of propagules by $P$. capsici. Jimenez and Lockwood (14) reported $7.8 \%$ germination of oospores in P. megasperma f. sp. glycinea in 1:1 (weight to volume) soil extract in contrast to $52.6 \%$ germination in $1: 10$ soil extract. It appears that high soil extract concentration could negatively affect germination of propagules. In this study, soil extract at $2 \%(1: 50)$ was selected by taking into consideration the results of Jimenez and Lockwood (14).

All soil samples examined in this study were receptive to P. capsici as gauged by the production of sporangia and zoospores. Other studies have categorized soils in terms of suppressive and nonsuppressive to species of Phytophthora, including $P$. capsici. In Taiwan, Ann (2) found soils that were suppressive to three Phytophthora spp., including P. capsici, based on germination of sporangia and reported that soils with $\mathrm{pH}<7$ were more suppressive than soils with $\mathrm{pH}>7$. In this study, $86 \%$ of soil samples had a $\mathrm{pH}>7$ whereas $14 \%$ of soil samples had a $\mathrm{pH}<7$, and production of propagules was similar in both groups of soils. Results from this study indicate that soils in New Mexico are conducive to $P$. capsici irrespective of $\mathrm{pH}$ level.

It should be realized that $P$. capsici is a genotypically and phenotypically diverse species $(10,20)$. It is plausible that the response observed in this study with isolate PWB24 may vary from that of other $P$. capsici isolates. However, P. capsici isolate PWB24 is the most virulent isolate routinely employed in the chile pepper breeding program for screening germplasms for disease resistance (5). Therefore, it is reasonable to assume that the response observed with this isolate may serve as a gauge of the behavior of $P$. capsici in soil across diverse environments. The response observed in this study provides a practical assessment for the highest potential risk associated with the presence of $P$. capsici in various soil environments.

This study has demonstrated the differential response of $P$. capsici to soils of different chemical composition. This result helps explain why disease outbreaks are observed after two to three cropping seasons on previously virgin soils. Crop rotation or shifting to virgin lands traditionally have been used to mitigate crop production problems such as reduced soil fertility and increased levels of pests and diseases arising from continuous use of land for a single crop. With respect to the $P$. capsici-pepper pathosystem, results indicate that cropping on virgin soils does not guarantee against outbreaks of $P$. capsici if the pathogen is naturally occurring or is introduced in virgin soils. Producers should be aware that virgin soils might be highly suitable to asexual reproduction of $P$. capsici and outbreaks of disease.

Another significant outcome of this study is that it provides an increased ecological understanding of the behavior of $P$. capsici in soils and demonstrates the usefulness of discriminant analyses and canonical correlation analyses in characterizing physical environments based on edaphic variables and soil receptivity to asexual reproduction of $P$. capsici.

\section{ACKNOWLEDGMENTS}

This work was financially supported by New Mexico State Agricultural Experimentation. I thank C. Sanogo and S. Thomas for reviewing this manuscript.

\section{LITERATURE CITED}

1. Alabouvette, C., Couteaudier, Y., and Louvet, J. 1982. Comparaison de la réceptivité de différents sols et substrats de culture aux fusarioses vasculaires. Agronomie 2:1-6.

2. Ann, P. J. 1994. Survey of soils suppressive to three species of Phytophthora in Taiwan. Soil Biol. Biochem. 26:1239-1248. 
3. Anonymous. 2004. New Mexico Chile production 2003. Online. New Mexico Department of Agriculture, New Mexico Agricultural Statistics.

4. Ayers, W. A., and Zentmyer, G. A. 1971. Effect of soil solution and two pseudomonads on sporangium production by Phytophthora cinnamomi. Phytopathology 61:1188-1193.

5. Bosland, P. W., and Lindsey, D. L. 1991. A seedling screen for Phytophthora root rot of pepper, Capsicum annuum. Plant Dis. 75:1048-1050.

6. Broadbent, P., and Baker, K. F. 1974. Association of bacteria with sporangium formation and breakdown of sporangia in Phytophthora spp. Aust. J. Agric. Res. 25:139-145.

7. Bowers, J. H., and Mitchell, D. J. 1990. Effect of soil-water potential and periodic flooding on mortality of pepper caused by Phytophthora capsici. Phytopathology 80:1447-1450.

8. Chakraborty, S., Thomas, M. R., and Ellis, N. 1995. A multivariate analysis of pathogenic variation in Colletotrichum gloeosporioides infecting the tropical pasture legume, Stylosanthes scabra. Phytopathology 86:283-289.

9. Duniway, J. M. 1976. Movement of zoospores of Phytophthora crytogea in soils of various textures and matric potentials. Phytopathology 66:877882.

10. Erwin, D. C., and Ribeiro, O. K. 1996. Phytophthora Diseases Worldwide. American Phytopathological Society, St. Paul, MN

11. Hair, J. F., Jr., Anderson, R. E., Tatham, R. L., and Black, W. C. 1998. Multivariate Data Analysis, 5th ed. Prentice Hall, Englewood Cliffs, NJ.

12. Hennessy, G. G., de Milliano, W. A. J., and McLaren, C. G. 1990. Influence of primary weather variables on sorghum leaf blight severity in southern Africa. Phytopathology 80:943-945.

13. Hord, M. J., and Ristaino, J. B. 1991. Effects of physical and chemical factors on the germination of oospores of Phytophthora capsici in vitro. Phytopathology 81:1541-1546.

14. Jimenez, B., and Lockwood, J. L. 1982. Germination of oospores of Phytophthora megasperma f. sp. glycinea in the presence of soil. Phytopathology 72:662-666.

15. Ko, W. H., and Nishijima, K. A. 1985. Nature of suppression of Phytophthora capsici in a Hawaiian soil. Phytopathology 75:683-685.
16. Larkin, R. P., Ristaino, J. B., and Campbell, C. L. 1995. Detection and quantification of Phytophthora capsici in soil. Phytopathology 85:10571063.

17. Matheron, M. E., and Porchas, M. 2000. Impact of azoxystrobin, dimethomorph, fluazinam, fosetyl-Al, and metalaxyl on growth, sporulation, and zoospore cyst germination of three Phytophthora spp. Plant Dis. 84:454-458.

18. Mehrlich, F. P. 1935. Nonsterile soil leachate stimulating to zoosporangia production by Phytophthora sp. Phytopathology 25:432-435.

19. Rasmussen, S. L., and Stanghellini, M. E. 1988. Effect of salinity stress on development of Pythium blight in Agrostis palustris. Phytopathology 78:1495-1497.

20. Ristaino, J. B. 1990. Intraspecific variation among isolates of Phytophthora capsici from pepper and curcubit fields in North Carolina. Phytopathology 80:1253-1259.

21. Sanogo, S. 2006. Predispositional effect of soil water saturation on infection of chile pepper by Phytophthora capsici. HortScience 41:172175.

22. Sanogo, S., and Carpenter, J. 2006. Incidence of Phytophthora blight and Verticillium wilt within chile pepper fields in New Mexico. Plant Dis. 90:291-296.

23. Sanogo, S., and Yang, X. B. 2004. Overview of selected multivariate statistical methods and their use in phytopathological research. Phytopathology 94:1004-1006.

24. Spicer, J. 2005. Making Sense of Multivariate Data Analysis. Sage Publications, Inc. Thousand Oaks, CA.

25. Stevens, J. 1992. Applied Multivariate Statistics for the Social Sciences, 2nd ed. Lawrence Erlbaum Associates, Publishers, Hillsdale, NJ.

26. Tamietti, G., and Pramotton, R. 1990. La réceptivité des sols aux fusarioses vasculaires: rapports entre résistance et microflore autochtone avec reference particulière aux Fusarium non pathogènes. Agronomie 10:69-76.

27. Workneh, F., van Bruggen, A. H. C., Drinkwater, L. E., and Shennan, C. 1993. Variables associated with corky root and Phytophthora root rot of tomatoes in organic and conventional farms. Phytopathology 83:581-589. 